\title{
A semi-automatic method for quantification of respiratory variation in early mitral inflow velocity using real time phase contrast cardiac magnetic resonance - normal values and clinical feasibility
}

Simon Thalén*, Peder Sörensson, Andreas Sigfridsson, Martin Ugander

From 19th Annual SCMR Scientific Sessions

Los Angeles, CA, USA. 27-30 January 2016

\section{Background}

Echocardiography has shown that patients with constrictive pericarditis or hemodynamically significant pericardial effusion show an increased respiratory variation in early transmitral inflow velocity. The methodology for quantification of respiratory variation in early transmitral inflow velocity using real time phase contrast (RT-PC) cardiovascular magnetic resonance (CMR) images is currently cumbersome and manual. The aim of this study was to develop a method for quantifying the respiratory variation in early transmitral inflow velocity using semiautomatic analysis of RT-PC CMR images.

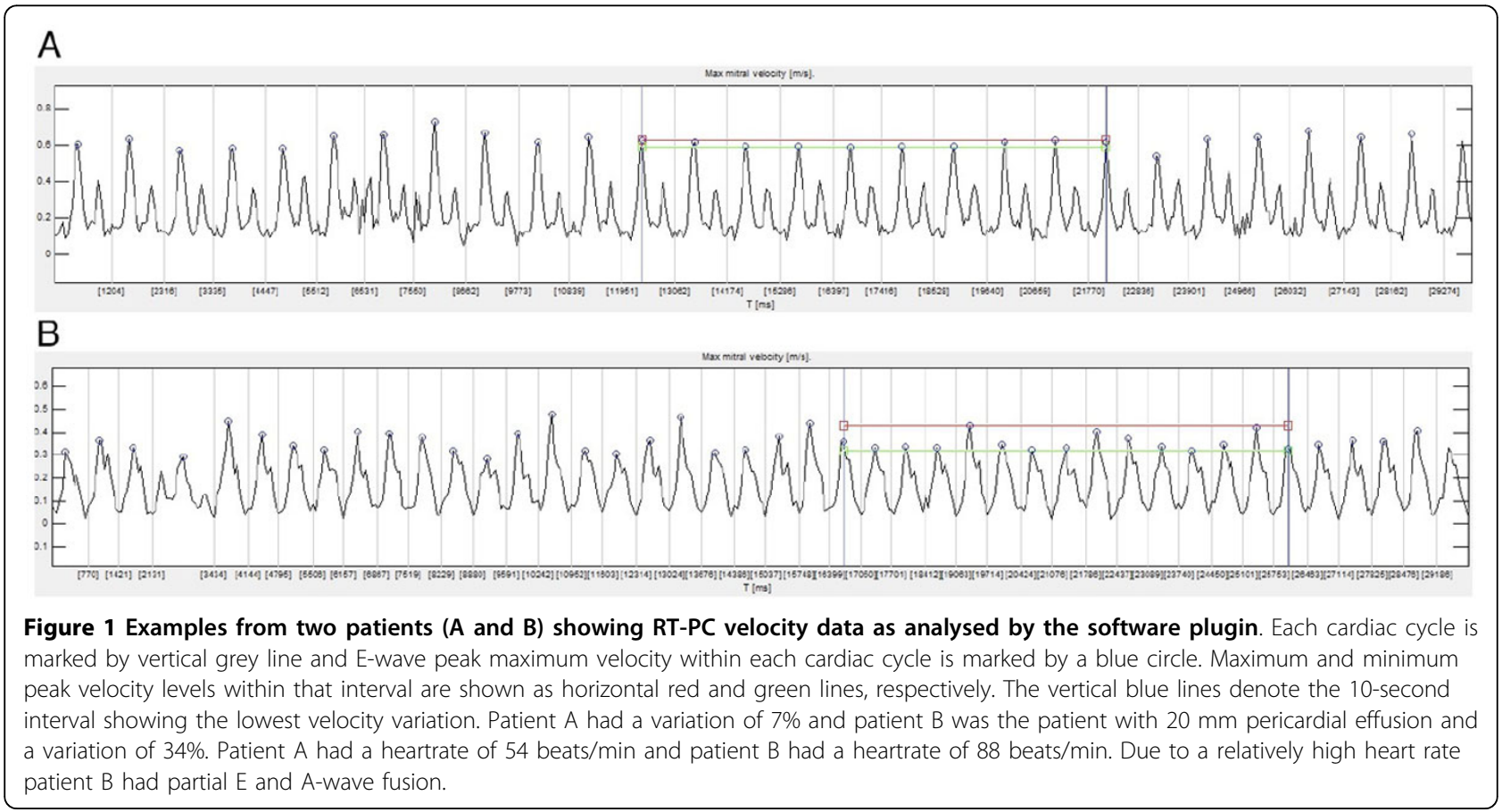

Department of Clinical Physiology, Karolinska Institute, Stockholm, Sweden

(c) 2016 Thalén et al. This is an Open Access article distributed under the terms of the Creative Commons Attribution License (http:// 


\section{Methods}

Clinically referred patients ( $n=25$, age $55 \pm 21$ years, $72 \%$ male) with sinus rhythm and no pericardial effusion or pericardial thickening underwent RT-PC CMR (1.5T Siemens Aera) of short-axis through-plane transmitral inflow velocities over two $30 \mathrm{~s}$ acquisitions during free breathing. Image acquisition parameters were: repetition time $12 \mathrm{~ms}$, water excitation pulse with flip angle $15^{\circ}$, slice thickness $11 \mathrm{~mm}$, matrix $84 \times 128$, echo-planar imaging factor 7, temporal sensitivity encoding rate 3, aliasing velocity $150 \mathrm{~cm} / \mathrm{s}$, shared velocity encoding enabled and temporal resolution $60 \mathrm{~ms}$. One patient with hemodynamically significant pericardial effusion was imaged to illustrate clinical feasibility. Image analysis was performed using an in-house developed plugin to Segment (Medviso $\mathrm{AB}$, Lund, Sweden). The user manually delineated a region of interest encompassing the mitral orifice, and the software then automatically identified the contiguous $10 \mathrm{~s}$ period of time with the lowest variation in per-beat peak early transmitral inflow velocity.

\section{Results}

Automatic analysis of RT-PC data yielded a respiratory variation in early mitral inflow velocity of mean \pm SD 16 $\pm 5 \%, 95 \%$ normal limits $6-26 \%$. The patient with pericardial effusion $(20 \mathrm{~mm})$ had an inflow variation of $34 \%$.

\section{Conclusions}

This study has demonstrated clinical feasibility and presented normal values for semi-automatic analysis of the respiratory variation in early transmitral inflow velocity using RT-PC CMR. Further studies in patients with echocardiographically verified hemodynamically significant pericardial disease are justified.

\section{doi:10.1186/1532-429X-18-S1-Q70}

Cite this article as: Thalén et al:: A semi-automatic method for quantification of respiratory variation in early mitral inflow velocity using real time phase contrast cardiac magnetic resonance - normal values and clinical feasibility. Journal of Cardiovascular Magnetic Resonance 2016 18(Suppl 1):Q70.

\section{Submit your next manuscript to BioMed Central} and take full advantage of:

- Convenient online submission

- Thorough peer review

- No space constraints or color figure charges

- Immediate publication on acceptance

- Inclusion in PubMed, CAS, Scopus and Google Scholar

- Research which is freely available for redistribution

Submit your manuscript at www.biomedcentral.com/submit 